\title{
A integração curricular no ensino fundamental e suas implicações para o currículo de formação de professores
}

\author{
Helena Maria dos Santos Felício \\ Universidade Federal de Alfenas | Brasil \\ Luísa Alonso \\ Universidade do Minho | Portugal
}

\section{Resumo}

O estudo apresenta uma análise sobre a integração curricular nos dispositivos legais que regem a Educação Básica Brasileira destinada aos anos iniciais do Ensino Fundamental, e as implicações destes dispositivos para o currículo de formação inicial de professores, destinado a esta etapa de escolarização. Fundamentados em Beane e Alonso, sobretudo em suas proposições acerca da integração curricular a análise realizou-se a partir de quatro categorias: Concepção alargada do currículo; Articulação do conhecimento de diferentes naturezas; Currículo enraizado no meio envolvente e Currículo como projeto educativo. $\bigcirc$ trabalho identifica que a integração curricular é preterida no processo de escolarização do ensino fundamental e aponta

12 a necessidade desta mesma perspectiva curricular nortear a formação inicial dos professores, na convicção de que este modelo possibilita uma progressiva e consistente integração significativa de saberes, procedimentos e atitudes dotando os futuros professores de competências que orientem a prática profissional.

Palavras-chave: Integração curricular. Ensino fundamental. Formação de professores.

\section{The curriculum integration in Brazilian fundamental education and its implications to the graduation curriculum of teachers}

\section{Abstract}

The study presents an analysis about the curriculum integration in legal devices that run the Brazilian basic education destined for initial years of Fundamental Education, these devices' implications to curriculum of initial teacher training, destined for this schooling step. It is grounded on Beane and Alonso, above all in their propositions about curriculum integration; the analysis has come up with four categories: Wide curriculum conception; Liaison between knowledge of distinct natures; Curriculum rooted on the engaging environment and Curriculum as an educational project. The work identifies that the curriculum integration is forgotten during the schooling process of Fundamental Education and points the need of this same curriculum perspective to guide the initial teacher training, with the certainty this model allows a progressive, 
solid and meaningful integration of knowledge, procedures and behaviors, endowing the future teachers with abilities which will guide their professional exercise.

Keywords: Curriculum integration. Fundamental education. Teacher training.

\section{La integración curricular en la enseñanza fundamental y sus implica- ciones para el currículo de formación de profesores}

\section{Resumen}

El presente estudio analiza los aspectos de la integración curricular presentes en los dispositivos legales que orientan la enseñanza fundamental brasileña y su implicación en el currículo de formación de profesores destinados a actuar en esta etapa de escolarización. Fundamentado en Beane y Alonso, principalmente en sus proposiciones acerca de la integración curricular, el análisis se realizó a partir de cuatro categorías: Concepción ensanchado del currículo; Articulación de conocimientos de diferentes naturalezas; Currículo enraizado en el medio envolvente y Currículo como proyecto educativo. El trabajo identifica que la integración curricular es preterida en el proceso de la enseñanza fundamental y apunta hacia la necesidad de que esta perspectiva curricular norteé la formación inicial de profesores, una vez que se cree que este modelo posibilita una progresiva y consistente integración significativa de saberes, procedimientos y actitudes, dotando a los futuros profesores de competencias que orienten su práctica profesional.

Palabras clave: Integración curricular. Enseñanza fundamental. Formación de profesores.

\section{Introdução}

Este texto tem por objetivo apresentar uma análise sobre a integração curricular nos dispositivos legais que regem a Educação Básica Brasileira destinada aos anos iniciais do Ensino Fundamental, e as implicações destes dispositivos para o currículo de formação inicial de professores, destinado a esta etapa de escolarização.

A articulação destes dois contextos formativos - anos iniciais do Ensino Fundamental e formação inicial de professores - justifica-se pelo vínculo visceral que um mantém com o outro, bem como pela convicção de que o contexto destas etapas de escolarização, deve provocar, condicionar, alimentar e sustentar a formação inicial de professores. 
A integração curricular no ensino fundamental e suas implicações para o currículo de formação de professores

Esta articulação também se justifica, por presenciarmos propostas de mudanças nas políticas educativas, não só na organização curricular, em um sentido mais amplo, como também na forma de gestão deste currículo em sala de aula.

Para Moreira (2000), esta gestão do currículo faz sentido quando professores e alunos se assumem enquanto sujeitos protagonistas do currículo, construindo-o no cotidiano escolar, mediante um processo democrático que produz situações de aprendizagens significativas para toda comunidade escolar.

Neste processo, não são, somente, os conteúdos disciplinares que devem compor o currículo, muito pelo contrário, a ressignificação da cultura local e a valorização das particularidades dos contextos devem fazer parte na construção e gestão do currículo escolar (PARO, 2011 ).

E este é um movimento que, segundo o mesmo autor, deve fazer parte do processo de formação inicial de professores, corroborando, assim, com a flexibilização curricular necessária aos processos formativos.

Da mesma forma, pesquisas recentes (GATTI, 2011 ) têm apontado certa estagnação na organização curricular dos cursos de formação inicial de 14 professores, que ainda se mantém arraigada numa visão disciplinar, que valoriza de forma diferenciada a "teoria" e a "prática", contribuindo para que uma concepção dicotômica no processo de formação.

Cyrino e Souza Neto (2014), ao apresentar experiências nacionais e internacionais do estágio curricular supervisionado, evidencia que este componente curricular pode contribuir para que a superação desta dicotomia se efetive a partir do estreitamento da relação entre Universidade-Escola no processo de formação inicial de professores, de modo que a escola se assuma, também, como instituição formadora.

Para além deste componente curricular, estudiosos do campo defendem a necessidade de centrar a formação inicial de professores na profissão, valorizando o conhecimento profissional docente e reconstruindo o espaço acadêmico de formação (NÓVOA, 201 2), de modo que o mesmo incorpore o conhecimento da prática profissional ao currículo formativo (ZEICHNER, 2010) a partir de uma relação mais equilibrada e dialética entre o conhecimento acadêmico e o da prática profissional.

Desta forma, ao olharmos para o processo de escolarização dos anos iniciais do Ensino Fundamental, temos que olhar, também, para a formação 
inicial de professores, pois, se não ultrapassarmos esta concepção dicotómica persistente, pouco avançaremos em direção de uma sólida formação que integre os diferentes componentes necessários à construção de um saber profissional significativo e relevante.

Para tanto, elegemos como corpus de análise os dispositivos legais que regulamentam Ensino Fundamental e, consequentemente os anos iniciais desta etapa de escolarização. Em linhas gerais, tais dispositivos apontam para o desenvolvimento de um trabalho formativo menos fragmentado, na perspectiva de integrar conhecimentos de diferentes naturezas no processo de ensino e de aprendizagem, de modo que tal processo seja mais relevante para compreensão relacional do mundo e para o desenvolvimento integral da pessoa.

Do mesmo modo, diversos autores (ALONSO, 2002; BEANE, 2002) apontam a integração curricular como aquela que, ao superar as limitações do currículo disciplinar, procura a unidade e a convergência de diferentes saberes a fim de que eles permitam a construção de conhecimentos mais articulados, significativos e relevantes por parte do sujeito aprendente. Assim, em termos de desenvolvimento curricular, conceber um currículo segundo uma perspectiva integrada de formação tem sido considerado a maneira mais adequada para se trabalhar com o conhecimento nas instituições educativas.

Neste sentido, esta análise dos dispositivos legais dos anos iniciais do Ensino Fundamental quer, em primeiro lugar, trazer à tona a maneira como a questão da integração curricular é assumida e perspectivada como orientação para o desenvolvimento curricular. Em segundo lugar, apresentar algumas implicações desta abordagem para a organização do currículo na formação inicial de professores, considerando que, sendo a ação do professor nesta etapa de escolarização, marcada pela monodocência, se torna imprescindível que os currículos da formação inicial incorporem abordagens e experiências integradoras em suas estruturas curriculares.

\section{A integração curricular nos dispositivos legais}

A legislação que rege o processo de educação escolarizada no Brasil faz indicações para que o currículo seja estruturado de forma integrada, a fim de ser superado o trabalho disciplinar que, por muito tempo, tem determinado nossos sistemas de ensino.

Neste trabalho, assumimos a integração curricular, 
A integração curricular no ensino fundamental e suas implicações para o currículo de formação de professores

[... ] como uma teoria da concepção curricular que está preocupada em aumentar as possibilidades da integração pessoal e social através da organização de um currículo à volta de problemas e de questões significativas, identificadas de forma colaborativa pelos educadores e jovens, independentemente das linhas de demarcação das disciplinas (BEANE, 2002, p. 30).

Esta maneira de conceber o currículo difere em sua essência das abordagens do currículo disciplinar ou academicista. Nestas, os conteúdos disciplinares, previamente selecionados, no interior de uma área de conhecimento, ao serem apresentados aos educandos, em estruturas fragmentadas e descontextualizadas da realidade, acabam por serem assumidos como informações com a finalidade em si mesmos. Ou seja, aprende-se, não para melhor compreender-se a si mesmo e a realidade, mas para obter resultados positivos em exames.

A integração curricular, ao centrar o currículo na própria vida, no contexto e na problemática do cotidiano, trabalhando "a partir de uma visão de aprendizagem como a integração contínua de novos conhecimentos e experiências, para aprofundar e alargar o nosso entendimento de nós mesmos e 16 do nosso mundo" (BEANE, 2002, p. 29), organiza os diversos conteúdos disciplinares em interação com questões significativas para os estudantes, favorecendo as relações entre esses conteúdos, e a "[...] sua utilidade convergente para compreender e agir sobre a realidade" (ROLDÃO, 2009, p. 193).

Não se trata, somente, de uma metodologia diferenciada de trabalho. cerne da integração curricular está na concepção de um currículo coerente, construído a partir de um princípio democrático, onde conteúdos e processos são articulados permitindo que as experiências educativas, sempre diversas e plurais, adquiram um sentido pessoal e social, tornando-as significativas para a formação integral dos educandos.

Para Alonso (2002) tal integração acontece quando todos os componentes do currículo e os diferentes contextos e processos de intervenção estiverem conjugados, de forma sistêmica. Neste sentido, a autora explicita um modelo de integração curricular que articula as seguintes dimensões: (a) a diversidade dos educandos com o seu potencial de aprendizagem e experiências prévias; (b) a pluralidade do conhecimento proveniente dos diferentes campos e domínios do saber e da experiência; (c) as potencialidades do meio 
envolvente local e global; e (d) a instituição educativa e os seus profissionais trabalhando de forma colaborativa.

À luz desta compreensão, elegemos como corpus de análise os seguintes dispositivos legais brasileiros: Constituição Federal Brasileira (BRASIL, 1988), Leis de Diretrizes e Bases da Educação Nacional (BRASIL, 1996) e as Diretrizes Curriculares Nacionais para o Ensino Fundamental (BRASIL, 2010).

Nestes documentos, identificamos elementos que se aproximam dos propósitos da integração curricular, efetuamos um primeiro ordenação das informações, selecionamos aquelas que nos pareciam mais pertinentes e realizamos a análise do conteúdo, a partir do modelo fechado (LAVILLE; DIONNE, 1999), a partir de quatro grandes categorias, consideradas essenciais nesta perspectiva da integração curricular que, por sua vez, foram subdividas em subcategorias, como mostra o quadro abaixo:

\section{Quadro 1}

\section{Quadro de categorias}

\begin{tabular}{|l|c|l|}
\hline \multicolumn{1}{|c|}{ Categorias } & Identificação & \multicolumn{1}{|c|}{ Subcategorias } \\
\hline $\begin{array}{l}\text { Concepção alargada } \\
\text { de currículo }\end{array}$ & A-1 & $\begin{array}{l}\text { Formação integral para o exercício da } \\
\text { cidadania }\end{array}$ \\
\cline { 2 - 3 } & A-2 & Educação compreensiva e equitativa \\
\hline $\begin{array}{l}\text { Articulação do conhe- } \\
\text { cimento de diferentes } \\
\text { naturezas }\end{array}$ & B-1 & $\begin{array}{l}\text { Concepção pós-positivista do } \\
\text { conhecimento }\end{array}$ \\
\cline { 2 - 3 } & B-2 & Transversalidade e continuidade curricular \\
\cline { 2 - 3 } & B-3 & Aprendizagem construtiva e significativa \\
\cline { 2 - 3 } & B-4 & Metodologias integradoras e investigativas \\
\hline \multirow{2}{*}{\begin{tabular}{l} 
Currículo enraizado meio envolvente \\
\cline { 2 - 3 }
\end{tabular}} & C-1 & Abertura e diálogo com o território \\
\hline Currículo como proje- & D-1 & $\begin{array}{l}\text { A escola como comunidade de vida e de } \\
\text { aprendizagem }\end{array}$ \\
\cline { 2 - 3 } to educativo & D-2 & Trabalho colaborativo \\
\hline
\end{tabular}

Fonte | O quadro foi elaborado pelas autoras, a partir da produção de Alonso (200 1, 2002, 2004, 2007) que fundamenta a Integração Curricular como perspectiva metodológica de organização curricular nos anos iniciais do Ensino Fundamental. 
A integração curricular no ensino fundamental e suas implicações para o currículo de formação de professores

\section{1) Integração Curricular: concepção alargada de currículo}

A construção de uma concepção alargada de currículo é condição sine qua non para entender a integração curricular como uma orientação capaz de responder às exigências formativas apresentadas pela sociedade contemporânea, marcadas pela complexidade, provisoriedade e diversidade do conhecimento.

Entender o currículo como um mero instrumento que organiza o conhecimento em áreas estanques, tradicionalmente reconhecidas, reforça a ideia reducionista do mesmo como sendo um conjunto de conteúdos, organizados em disciplinas, assumido como verdade estática, que deve ser "transmitida" aos educandos, para os quais representa algo com pouca significatividade.

Em termos legais, podemos associar a concepção alargada de currículo, quando verificamos que a educação, direito assegurado pelo artigo 205 da Constituição Federal Brasileira (BRASIL, 1988), se apresenta como um conceito amplo, cujo processo objetiva o desenvolvimento pleno do sujeito, seu preparo para o exercício da cidadania e sua qualificação para o trabalho.

A educação para a cidadania é um pressuposto assumido pelos dis18 positivos legais da educação brasileira, por entender que este é o fim primeiro de tal processo. Ou seja, a educação "cumpre o seu papel" quando contribui para que os sujeitos construam condições de agir e reagir em seu contexto social. Entretanto, esta interpretação ampliada do processo educacional se materializa no contexto da educação escolarizada que, assumindo a denominação de Educação Básica pela Lei de Diretrizes e Bases da Educação Nacional, Lei n 9.394, de 20 de dezembro de 1996, "[...] tem por finalidade desenvolver o educando, assegurar-the a formação comum indispensável para o exercício da cidadania e fornecer-the meios para progredir no trabalho e em estudos posteriores" (BRASIL, 1996). Tal processo engloba três etapas: a educação infantil, o ensino fundamental e o ensino médio. Esta organização, mesmo que apresentada em etapas, evidencia o reconhecimento da importância da educação escolar para as diferentes fases da vida, de forma contínua e integrada.

A Lei n 9.394 indica, no artigo 32, que o Ensino Fundamental, "[... ] iniciando-se aos seis anos de idade, terá por objetivo a formação básica do cidadão" (BRASIL, 1996). Tais objetivos evidenciam a necessidade de um trabatho educacional que, percepcionando a criança como um todo globalizante, 
promova o seu desenvolvimento em diferentes dimensões e a sua formação para o exercício da cidadania. Para tanto, faz-se necessário alargar a concepção de currículo e compreender que o trabalho educativo deve incorporar conhecimentos que estão para além daqueles estruturados pelas disciplinas tradicionais (Português, Matemática, Ciências Naturais, História, Geografia, Artes).

Tais conhecimentos selecionados e organizados nos manuais didáticos para serem "distribuídos" aos educandos de forma fragmentada e disciplinar, segundo Beane (2002), pouco tem contribuído para que estes sujeitos deem respostas significativas aos desafios do cotidiano da vida. Em geral, estes conhecimentos ficam à parte, marginalizados do contexto existencial destes sujeitos e, portanto, sem significado. Isto porque o trabalho, no interior destas disciplinas tradicionais, prioriza os conteúdos conceituais em detrimento dos procedimentais e atitudinais.

No entanto, alargar a concepção de currículo não significa "[...] incluir no currículo mais conteúdos, comprimindo ainda mais a experiência, mas antes para os tornar mais relevantes para a vida, numa sociedade de aprendizagem permanente" (ALONSO; SILVA, 2005, p. 46-47). Ou seja, é necessário assumir que o desenvolvimento integral no Ensino Fundamental, está implicado, muito mais na relação dos conteúdos com as experiências vitais e contextualizadas, do que com a quantidade dos mesmos, de forma que esses possibilitem os educandos "compreenderem e participarem na complexidade e dinamismo do mundo em que thes é dado viver, dando um sentido às aprendizagens e desenvolvendo competências e atitudes adequadas." (ALONSO, 2004a, p. 147).

Esta perspectiva se instala na convicção da necessidade de uma "educação de base" que, segundo Roldão (2009), proporciona aos sujeitos as aprendizagens consideradas essenciais para o prosseguimento do seu percurso educativo, como também àquelas que thes conferem o sentido de pertença a uma determinada sociedade.

Esta educação de base se torna efetiva, se o processo de escolarização for assumido como uma "educação compreensiva" que tem como característica essencial "[...] o manter juntos todos os alunos, sem segregá-los por especialidades nem por níveis de capacidade, aos quais é proposto um currículo comum, seja qual for a sua condição social, gênero, capacitação, 
A integração curricular no ensino fundamental e suas implicações para o currículo de formação de professores

credo religioso, etc." (SACRISTÁN, 2001 , p. 84). Ou seja, refere-se a um processo educacional em que todos os sujeitos tem direito a um currículo que the assegure acesso aos bens sociais sem exclusão ou marginalização.

As Diretrizes Curriculares Nacionais para o Ensino Fundamental (DCNEF) apresentam esta necessidade evocando a oferta de uma "educação compreensiva" de qualidade, relevante, pertinente e equitativa para todos ao afirmar que:

A educação de qualidade, como um direito fundamental, é, antes de tudo, relevante, pertinente e equitativa: I - A relevância reporta-se à promoção de aprendizagens significativas do ponto de vista das exigências sociais e de desenvolvimento pessoal. II - A pertinência refere-se à possibilidade de atender às necessidades e às características dos estudantes de diversos contextos sociais e culturais e com diferentes capacidades e interesses. III - A equidade alude à importância de tratar de forma diferenciada o que se apresenta como desigual no ponto de partida, com vistas a obter desenvolvimento e aprendizagens equiparáveis, assegurando a todos a igualdade de direito à educação (BRASIL, 2010).

20 Percebemos, ainda, que a educação compreensiva se instala no cotidiano da sala de aula, uma vez que cabe ao professor, como indica o artigo 26 das DCNEF, fornecer aos educandos

[...] instrumentos mais complexos de análise da realidade que possibilitem o acesso a níveis universais de explicação dos fenômenos, propiciando-thes os meios para transitar entre a sua e outras realidades e culturas e participar de diferentes esferas da vida social, econômica e política (BRASIL, 2010).

É importante salientar que conceber o currículo de forma alargada, nesta dimensão da educação compreensiva, contribui para que este sujeito se sinta integrado ao complexo contexto da realidade contemporânea, bem como o capacita para que tenha condições de analisar criticamente este contexto, assumindo-se como sujeito de direitos e responsabilidades e, consequentemente, corresponsável pelos diferentes movimentos desta realidade. 


\section{2) Integração Curricular: articular o conhecimento de diferentes naturezas}

A segunda categoria considerada neste estudo diz respeito à capacidade de articular conhecimentos de diferentes naturezas no currículo, a partir de uma concepção pós-positivista do conhecimento, que é entendida enquanto processo complexo e dinâmico, em função das exigências da sociedade contemporânea que interpela a utilização de conhecimentos provenientes de diferentes fontes, tratados de forma interdisciplinar.

A nossa concepção de integração curricular é muito mais complexa e abrangente, na medida em que não considera apenas o conhecimento normalmente associado às disciplinas escolares que vem influenciado pelo que se designa como conhecimento acadêmico. Admite a possibilidade de mobilização de todos os tipos de conhecimento que possam contribuir para que o aluno compreenda melhor o mundo à sua volta e se compreenda melhor a si próprio, enquanto individuo e cidadão (ALONSO; SOUSA, 2013 , p. 54).

A articulação do conhecimento de diferentes naturezas, expressa na legislação educacional brasileira para o Ensino Fundamental, aponta para dois movimentos: um primeiro, que indica a necessidade de articular o conhecimento trabalhado nas instituições educacionais com aquele proveniente da experiência e do cotidiano, o que Alonso (2004) denomina de "articulação lateral", necessária para que o conhecimento tenha significado e seja relevante.

Um segundo, que reforça a convergência dos saberes disciplinares, organizados nas diferentes áreas do conhecimento numa perspectiva de transversalidade e continuidade curricular, implicando uma "articulação vertical e horizontal" entre ciclos e áreas de conhecimento a fim de que o desenvolvimento do educando "[...] obedeça a um continuum de aprofundamento e complexidade crescentes." (ALONSO; SOUSA; GONCCALVES; MEDEIROS; CARVALHINHO, 2011 , p. 111.

Em relação ao primeiro movimento, é possível perceber a explicitação dessas articulações de conhecimentos de diferentes naturezas nas DCNEF, quando, ao tratar sobre a organização curricular, indica no artigo 9, que o currículo deve ser compreendido como "[...] experiências escolares que se desdobram em torno do conhecimento, permeadas pelas relações sociais, 
A integração curricular no ensino fundamental e suas implicações para o currículo de formação de professores

articulando vivências e saberes dos estudantes com os conhecimentos historicamente acumulados" (BRASIL, 2010).

Ao assinalar tal perspectiva de integração, as diretrizes apontam para a necessidade de "[...] avançar na construção de um conhecimento capaz de enriquecer a simplificação do cotidiano e de ultrapassar a especialização do conhecimento científico" (ALONSO, 2002, p. 67), quando indica a necessária articulação do conhecimento sistematizado com as vivências e experiências dos educandos.

Esta articulação torna o processo de aprendizagem signiticativo, na medida em que os conteúdos trabalhados se relacionem com os esquemas de conhecimento já construídos pelos educandos em suas experiências anteriores, ampliando suas capacidades cognitivas para a resolução dos problemas apresentados pelo cotidiano existencial, dentro e fora da escola.

segundo movimento de articulação do conhecimento, aponta para a necessária transversalidade e continuidade curricular. Como podemos verificar, as DCNEF, no $2^{\circ}$ parágrafo, do artigo 16, define que a "[...] transversalidade constitui uma das maneiras de trabalhar os componentes curriculares, 22 as áreas de conhecimento e os temas sociais em uma perspectiva integrada" (BRASIL, 2010).

Estas propostas sugeridas pelas diretrizes indicam que a construção do currículo em sala de aula deve pautar-se em um trabalho interdisciplinar que assegure a transversalidade do conhecimento, em uma perspectiva integrada. Entretanto, sabemos que existem diferentes níveis e formas de integração na proposta interdisciplinar que vão das mais elementares, como a contribuição de cada disciplina para um determinado tema ou problema, até modos mais elevados, "[...] em que o nível de coordenação é tal que desaparecem os limites entre as disciplinas, constituindo-se uma espécie de macrodisciplina" (AlONSO, 2002, p. 66). Esta diversidade é percepcionada, ao longo da história do processo de escolarização, sobretudo a partir do movimento da Escola Nova, quando identificamos diferentes iniciativas que intentaram trabaIhar o currículo de forma integrada.

As DCNEF orientam que tal integração deve ser efetivada mediante a articulação da base nacional comum e a parte diversificada do currículo que deve constituir-se enquanto processo que privilegia um continuum, articulados entre si ao longo de todo Ensino Fundamental. 
A concretização desta continuidade curricular, indicada pela legislação, requer, por um lado, o entendimento da não existência de fronteiras rígidas entre os diferentes contextos de aprendizagens do educando. Por outro lado, este continuum deve ser sustentado pelo equilíbrio no processo formativo, - que requer que estas transições sejam bem sucedidas e orientadas pelo trabalho colaborativo entre os professores (ROLDÃO, 2009).

Para além deste aspecto relacional, a defesa deste continuum no contexto de aprendizagem formal se fortalece na medida em que se solidifica a compreensão de que o desenvolvimento é resultado de complexas relações sociais, culturais, emocionais e cognitivas, que o educando estabelece com as pessoas e com o meio, e, portanto, fundacional e globalizante. Assim, ele será tanto melhor quanto mais este educando for assumido como um sujeito/ aprendiz, "inteiro" e ativo, com necessidade incessante de novas experiências.

Ser assumido como sujeito significa compreender o educando como co-construtor e re-construtor de conhecimento e da experiência, na certeza de que este processo se desenvolve em seu interior, mediante as relações cognitivas que este sujeito faz.

No entanto, o qualificativo "co-" indica que o educando constrói e reconstrói o conhecimento "com", na relação interativa com o outro, no trabatho colaborativo e em parceria com os professores e demais educandos, em intensa relação com o objeto de conhecimento. $\bigcirc$ que implica a necessidade dos professores, em conjunto com seus alunos, colocarem-se "[...] numa postura de investigação e reflexão perante o currículo, de maneira a permitir a adequação das orientações curriculares de âmbito nacional às necessidades do seu contexto específico" (ALONSO, 200 1, p. 12).

Este reconhecimento do educando como sujeito do processo de ensino e de aprendizagem faz sentido se as escolas e seus currículos forem "[...] experienciados como locais seguros, estimulantes e motivantes, de construção de conhecimentos significativos" (PORTUGAL, 2009, p. 49), proporcionando tarefas que permitam o estabelecimento de ligações com esquemas mentais que a criança já possui.

Esta dimensão é percebida no artigo 26, das DCNEF, quando afirma que os sistemas de ensino e as escolas devem assegurar "[...] um ambiente propício à aprendizagem, com base: na contextualização dos conteúdos, 
A integração curricular no ensino fundamental e suas implicações para o currículo de formação de professores

assegurando que a aprendizagem seja relevante e socialmente significativa" (BRASIL, 2010).

Esta aprendizagem significativa e relevante, tem sido, muitas vezes, interpretada como o trabalho com temas familiares, do agrado dos educandos, de caráter prático/utilitário. No entanto, a relevância necessária, no interior da concepção da integração curricular, diz respeito à utilidade social do que é aprendido. Ou seja, "[...] implica a possibilidade de ser mobilizado adequadamente pelo sujeito, articulado, usado e/ou questionado em novas situações, sustentador da possibilidade de novo conhecimento, gerador de mais e melhores competências no sujeito" (ROLDÃO, 2013, p. 23).

Desta forma as diretrizes apontam que é de responsabilidade da escola e dos professores construir percursos curriculares formativos em que seja possivel transformar os conhecimentos relevantes para a sociedade em conhecimentos relevantes para os educandos, garantindo que a aprendizagem seja construtiva e significativa.

Uma das abordagens metodológicas favorecedoras da integração curricular que se tem mostrado com eficácia na aprendizagem construtiva e significativa, no interior do currículo integrado, são as "atividades integradoras" que,

[...] estruturadas em torno de problemas sócio-naturais significativos (questão geradora), desencadeiam todo um percurso de actividades interligadas e articuladas, tanto vertical como horizontal e lateralmente, no sentido de procurar respostas adequadas, utilizando para isso os diferentes instrumentos conceptuais e metodológicos das áreas ou disciplinas e outros existentes no meio envolvente (ALONSO, 2001, p. 13).

Nesta proposta metodológica, professores e alunos, ao trabalharem os conteúdos do currículo, assumem um papel de investigadores, de tal modo que tais conteúdos sejam apreendidos com significado e sentido pessoal e coletivo, por meio de situações-problemas que favoreçam a integração de conhecimentos, uma vez que a integração curricular demanda visão global e diferenciada do aluno enquanto pessoa repleta de capacidades que devem ser exploradas e desenvolvidas (ROEGIERS, 2006).

Embora, os dispositivos legais utilizados neste estudo não apresentem indicações sobre as características das atividades a serem desenvolvidas em 
sala de aula, é possível inferir que os artigos 27 e 30 das DCNEF apontam para as "atividades integradoras" quando orienta que os professores devem adotar formas de trabalhar de modo que considerem as características dos educandos, que proporcionem maior mobilidade dos mesmos no espaço escolar, que os levem a explorar diferentes linguagens e a manusear diferentes materiais, que as atividades mobilizem o raciocínio, as atividades investigativas, a articulação entre a escola e a comunidade (BRASIL, 2010).

Desta forma, a relevância das "atividades integradoras" se instaura no sentido de favorecer que os conteúdos trabalhados na escola contribuam para que os educandos possam estar como sujeitos neste contexto social contemporâneo, cada vez mais complexo e interativo que demanda diferentes formas de aceder ao conhecimento e exige deles uma adaptação flexível, crítica e criativa.

\section{3) Integração Curricular: currículo enraizado no meio envolvente}

A terceira categoria, assinalada neste trabalho, faz jus à sua capacidade de abertura, de reconhecimento e de diálogo do currículo com o meio envolvente em que o mesmo se encontra enraizado, a fim de que a intersecção "currículo - território" atinja níveis em que o primeiro seja construído "a partir de" e "em interação com" os problemas, as situações e os acontecimentos originários no segundo.

artigo 16, das DCNEF, aponta a necessária articulação entre o conhecimento oficial com a "[...] realidade local, as necessidades dos alunos, as características regionais da sociedade, da cultura e da economia" (BRASIL, 2010), além de afirmar, no artigo 24, "[...] a necessária integração dos conhecimentos escolares no currículo favorece a sua contextualização e aproxima o processo educativo das experiências dos alunos" (BRASIL, 2010).

Estas proposições sugerem um deslocamento do ponto central nas orientações do trabalho em sala de aula. Ou seja, segundo Beane (2002), as atividades são planejadas, muito mais, a partir das preocupações dos educandos do que dos guias de conteúdos sequenciados e predeterminados nas organizações curriculares disciplinares. Neste sentido, tais preocupações estão intimamente relacionadas com as experiências vivenciadas no cotidiano e são elas que direcionam as atividades em sala de aula, possibilitando que os conteúdos disciplinares sejam evocados na medida em que forem necessários, 
A integração curricular no ensino fundamental e suas implicações para o currículo de formação de professores

colaborando para que os conteúdos e as atividades pedagógicas sejam significativos no processo de aprendizagem.

Não se trata de um percurso fácil de ser construído, contudo faz-se necessário, uma vez que o sucesso do processo de aprendizagem se instaura no grau de significância atribuído pelos educandos às atividades escolares. E, quanto mais próximas do território forem tais atividades escolares, mais significativas elas serão e, portanto, facilitadoras da relevância e funcionalidade da aprendizagem que elas proporcionam.

Deste modo é que podemos afirmar que no processo de integração curricular é necessário "[...] partir da realidade, construir e reconstruir conhecimento sobre ela através da atividade e voltar de novo à realidade" (ALONSO, 2002 , p. 70). Este ciclo, ao mesmo tempo em que se mostra constante e progressivo, é fundamental para a aprendizagem significativa, uma vez que os educandos encontram relevância no que fazem no interior das instituições educacionais e, permite que elas não se estruturem como instituições paralelas, divorciadas da realidade.

Esta inserção da escola no meio traz como consequência a necessidade de constituir uma comunidade educativa mais ampliada que, para além dos professores, seja capaz de envolver os familiares e demais membros da comunidade, mediante a abertura e o diálogo, na certeza de que a escola não é uma instituição total. É preciso considerar que, no atual contexto, que se mostra cada vez mais globalizado, ela não é a única instituição responsável pela educação dos sujeitos, reconhecendo, assim, que precisa de outros espaços, de outras práticas, de outros sujeitos que compartilhem o mesmo ideal educativo (FELÍCIO, 201 2).

Esta implicação é percebida no artigo 20 das DCNEF, quando apresenta a necessária integração dos profissionais da educação, dos estudantes, das famílias, dos agentes da comunidade interessados na educação (BRASIL, 2010 ) como requisito fundamental para que a escola se estabeleça enquanto uma instituição com qualidade social.

Sacristán (2008, p. 132), ao apresentar a defesa de que a "escola não é o único agente que educa", enfatiza que ela é desafiada, neste novo contexto, a se assumir enquanto uma instituição que se coloca em permanente relação de complementaridade com os demais "agentes" socio-educativos Ifamília, meios de comunicação, tecnologias de informação, oferta cultural do 
meio ambiente), sendo necessário reconstruir sua função, abrindo-se para a formação de uma comunidade educativa, "[...] inter-relacionando a cultura trabalhada em seu interior com a que circula e se obtém procedente de outros canais de difusão" (SACRISTÁN, 2008, p. 144).

Desta forma, instituir a comunidade educativa nesta ótica mais enraizada, implica, não só a valorização dos diferentes contextos e experiências de aprendizagens, como a exploração das potencialidades formativas de cada contexto, como também, avançar para uma abordagem do processo educativo onde seja possível a construção de "[...] contextos socioeducativos e pedagógicos estimulantes e integrados, que se constituam como territórios de vida e de aprendizagem, de cuidado e educação, de construção de subjetividades e identidades, de socialização e emancipação" (ALONSO, 2007, p. 335), no envolvimento de outros sujeitos, outros tempos e outros espaços.

\section{4) Integração Curricular: currículo como projeto educativo}

A quarta categoria a ser considerada sobre a integração curricular diz respeito à visão de um currículo, consubstanciado em um projeto educativo, desenvolvido enquanto cultura que se sustenta "[...] na procura de uma visão estratégica partilhada, centrada na qualidade das aprendizagens, que se constrói com base na participação de todos os atores a partir da ação refletida e avaliada, de forma contínua" (ALONSO, 2004b, p. 150).

Esta premissa pode ser considerada a partir de dois aspectos que se complementam: na centralidade do projeto curricular, "[...] que fundamenta, articula e orienta as decisões sobre a intervenção pedagógica nas escolas com o fim de permitir uma mediação educativa de qualidade para todos os educandos" (ALONSO, 2001 , p. 3), e no trabalho colaborativo que, em diferentes níveis de desenvolvimento do currículo é construído enquanto espaço de comunicação, de negociação e de tomada de decisões, numa perspectiva de gestão colegial.

primeiro aspecto, traz para o centro da prática pedagógica o projeto curricular ou educativo que, ultrapassando a ideia de um conjunto de decisões técnicas, se assume enquanto processo contínuo de reflexão e ação, comprometido com a aprendizagem relevante e significativa dos educandos, em um constante movimento crescente. Deste modo, as atividades propostas e 
A integração curricular no ensino fundamental e suas implicações para o currículo de formação de professores

realizadas no contexto escolar, são efetivadas a partir de critérios intencionais e partilhados que respondam às necessidades reais de aprendizagem, e se apresentam em um sentido global à luz dos princípios definidos pelo próprio projeto.

Neste sentido, podemos entender que as DCNEF, quando em seu artigo 18, manifestam a exigência de se estruturar "[...] um projeto educativo coerente, articulado e integrado, de acordo com os modos de ser e de se desenvolver das crianças e adolescentes nos diferentes contextos sociais" (BRASIL, 2010), indicam a necessidade do currículo ser currículo enquanto projeto educativo, cuja construção deve estar sedimentada nas características dos sujeitos envolvidos e dos contextos nos quais ele será efetivado, portanto, excluindo toda a possibilidade de um currículo "prète a porter".

O segundo aspecto, do trabalho colaborativo, requer a democratização das relações em torno das decisões curriculares, favorecendo que a construção do currículo seja compartilhada por professores e educandos.

Embora a tradição curricular não reconheça os educandos como sujeitos, e também, decisores do currículo, é possível tornar tais decisões mais democráticas por intermédio de "[...] processos de negociação, construtiva e interativa entre alunos, professores e contexto natural, social e cultural, pondo em prática a ideia de um 'currículo negociado'" (ALONSO; SOUSA, 2013, p. 59). Isto implica necessariamente uma reorganização do trabalho escolar, enquanto uma oportunidade de repensar a escola e suas funções.

Para tanto, este aspecto evidencia que o planejamento em torno do saber e da experiência deve ser de competência dos professores e também dos educandos, no compartilhamento das decisões. Tal proposição é apontada pelas DCNEF, quando afirma, no artigo 25, que os professores deverão considerar

[...] a diversidade sociocultural da população escolar, as desigualdades de acesso ao consumo de bens culturais e a multiplicidade de interesses e necessidades apresentadas pelos alunos no desenvolvimento de metodologias e estratégias variadas que melhor respondam às diferenças de aprendizagem entre os estudantes $e$ às suas demandas (BRASIL, 2010).

Não se trata de efetivar um modelo espontaneista de ensino. Muito pelo contrário, trata-se de alinhar os objetivos propostos pelas diretrizes curriculares aos interesses dos alunos de modo que estes sejam trabalhados a partir 
de uma significatividade didática, estimulando a atitude científica diante da realidade, "[...] de forma a, progressivamente, ampliar e modificar as suas concepções, tornando a aprendizagem mais significativa, reflectida e funcional, e desenvolvendo um pensamento crítico e consistente sobre a mesma" (ALONSO, 2001 , p. 16).

Outra manifestação do trabalho colaborativo diz respeito às relações cooperantes estabelecidas entre os professores que, na perspectiva da integração curricular, supera o isolamento e o individualismo que marcam a atividade docente, para evoluir na direção do entendimento da escola enquanto unidade institucional colegial.

Desta forma, é necessário fomentar uma "cultura profissional colaborativa" (HARGREAVES, 1998; ROLDÃO, 2009) entre os professores que implica em ter metas partilhadas e assumidas pelo coletivo, bem como o desenvolvimento de um trabalho conjunto que exige, por um lado, um tipo de estrutura organizacional aberta e, por outro lado, permite aos professores participarem ativamente nas tomadas de decisões que favorecem o desenvolvimento profissional, a transformação reflexiva das práticas e a aprendizagem dos educandos.

Um indicativo desta dimensão é anunciado no parágrafo $4^{\circ}$, do artigo 20 das DCNEF, quando aponta a necessidade do trabalho colaborativo na ótica da gestão democrática como instrumento que horizontaliza as relações e favorece a convivência colegiada (BRASIL, 2010).

O trabalho colaborativo demarca, por assim dizer, um aspecto primordial da integração curricular, uma vez que exige disposição para o mesmo, abertura para o trabalho colegiado, superando o trabalho isolado em que muitos professores estão imersos para se atingir um nível de desenvolvimento curricular institucional. Ou seja, não basta uma única classe, de um determinado professor, atingir níveis excelentes de aprendizagens. É preciso que o "todo" da escola caminhe nesta perspectiva. O que só é possível a partir da criação de "culturas colaborativas" (FULLAN; HARGREAVES, 2001) e "comunidades de conhecimento e aprendizagem" (ESCUDERO, 2010). 
A integração curricular no ensino fundamental e suas implicações para o currículo de formação de professores

\section{Em caráter de (in) conclusão... as implicações da Integração Curricular para o currículo de formação de professores}

A partir desta análise dos dispositivos legais que regem os anos iniciais do Ensino Fundamental, na ótica da integração curricular, percebemos que esta concepção curricular é a pretendida neste nível de escolaridade, cuja especificidade da prática profissional é desenvolvida na perspectiva da monodocência.

Ancorados neste contexto, temos por hipótese que a concepção da integração curricular se transforma em prática se, no processo de formação dos professores, esta perspectiva se fizer "apreendida", no sentido de ser conhecida e aprofundada em seus aspectos epistemológicos e, sobretudo, "experimentada", no sentido de vivenciada durante este percurso de formação.

Assim, ao mesmo tempo em que defendemos que é importante orientar o processo de formação inicial de professores em uma dimensão mais integrada do currículo, também nos questionamos sobre quais seriam as implicações da Integração Curricular apresentada pela legislação da Educação Básica brasileira e analisadas neste trabalho, para o currículo de formação inicial de professores.

No Brasil, o curso de Pedagogia tem se constituído como o locus de formação de professor para os anos iniciais do Ensino Fundamental. O parecer emitido pelo Conselho Nacional de Educação à respeito de suas Diretrizes indica, em um dos seus princípios, que o graduando de Pedagogia deve trabalhar com um repertório de

[... informações e habilidades composto por pluralidade de conhecimentos teóricos e práticos, cuja consolidação será proporcionada pelo exercício da profissão, fundamentando-se em interdisciplinaridade, contextualização, democratização, pertinência e relevância social (BRASIL, 2005, p. 6).

Em outro momento, enfatiza que o curso deve oferecer formação para o exercício integrado e indissociável da docência (BRASIL, 2005); que a pluralidade de conhecimentos e saberes trabalhados durante o processo formativo devem sustentar a conexão entre sua formação inicial, o exercício da profissão e as exigências de educação continuada (BRASIL, 2005); e, finalmente, que os núcleos de estudos, dentre eles o núcleo de estudos integradores, devem 
proporcionar aos licenciandos, experiências cada vez mais complexas e abrangentes de construção de referências teórico-metodológicas próprias da docência, além de oportunizar a inserção na realidade social e laboral de sua área de formação (BRASIL, 2005).

Em linhas gerais, percebemos que estes indicativos para a formação do pedagogo/professor também se cruzam com as categorias de integração curricular, acima apresentadas e analisadas. $\bigcirc$ que nos reafirma a necessidade de, também conceber este processo de formação na perspectiva da integração curricular, sobretudo, porque, estudos apontam, por um lado, que "[...] o currículo proposto pelos cursos de formação de professores tem uma característica fragmentária, apresentando um conjunto disciplinar bastante disperso" (GATTI, 2010, p. 1371) e, por outro lado, a existência de um desequilíbrio na relação teoria-prática, favorecendo a dimensão teórica, bem como uma quase ausência da escola, como instituição social e de ensino, "[...] o que leva a pensar numa formação de caráter mais abstrato e pouco integrado ao contexto concreto onde o profissional-professor vai atuar" (GATTI, 2010, p. 1372).

Considerando que o Parecer sobre as Diretrizes do curso de Pedagogia assinala que é central o conhecimento da escola como uma organização complexa que tem uma função social e formativa (BRASIL, 2005) e que as instituições de formação devem trabalhar em interação sistemática com as escolas de educação básica, é possível inferir que os pressupostos indicados sobre a integração curricular presentes nos aportes legais, analisados anteriormente, devem ser assumidos, também, no processo de formação inicial de professores, para o qual apontamos as seguintes implicações:

1. Em relação à concepção alargada do currículo, inferimos que o processo de formação inicial de professores é constantemente desafiado a romper com a preponderância do modelo transmissivo. Ou seja, se o currículo de formação inicial se ater a tão somente ser um conjunto de objetivos, disciplinas e conteúdos a serem trabalhados com os formandos, o objetivo prioritário desta formação "[...] consistirá em proporcionar ao professor a aquisição de um repertório de habilidades e conhecimentos necessários para aplicar as diretrizes estabelecidas no âmbito do currículo prescrito" (FLORES, 2000, p. 151).

Pelo contrário, uma concepção mais alargada do currículo sugere um trabalho formativo que proporcione "[...] experiências de aprendizagem em 
A integração curricular no ensino fundamental e suas implicações para o currículo de formação de professores

que os formandos possam adquirir competências que sustentem um desempenho profissional adequado, nos diferentes domínios do perfil profissional que contribuem para o desenvolvimento educacional nas escolas" (ALONSO; SILVA, 2005, p. 51 1, fortalecido nas dimensões científicas, pedagógicas, sociais e culturais.

Tais dimensões contribuem para uma visão, também alargada, da própria profissionalidade docente que, nesta perspectiva, é reconhecida em sua dimensão ética e social, contribuindo para que o professor se assuma enquanto um "intelectual transformador" que, segundo Giroux (1997), se compromete com o processo de emancipação de si próprio e de seus educandos de modo que, na relação dialógica, se formem na perspectiva de atuarem como cidadãos ativos e críticos na sociedade em que estão inseridos.

2. Isto exige, em segundo lugar, superar a organização clássica das disciplinas apresentadas no curso de Pedagogia para articular o conhecimento de diferentes naturezas, no sentido vertical e horizontal dos diferentes componentes curriculares de um curso, "[...] de forma a permitir uma integração consistente e coerente dos diversos saberes, necessários à construção do perfil profissional 32 desejado" (ALONSO; SILVA, 2005, p. 54), superando a hierarquização, a fragmentação e a especialização do conhecimento, manifestada na rigidez e na compartimentação curricular.

3. É necessário que este currículo, construído a partir do conhecimento integrado, de forma consistente e coerente, seja enraizado no meio envolvente, mediante o estabelecimento de uma pluralidade de sinergias verticais e horizontais que mobilize, no processo de formação, os diferentes tipos de saberes acadêmicos, as experiências dos formandos e o contexto profissional. De forma prioritária, torna-se imprescindível redimensionar a Iniciação à Prática Pedagógica, presente nos cursos de formação de professores, fazendo com que a mesma se transforme numa dimensão nuclear no processo de formação, estruturada de tal forma que garanta ao formando a integração dos diferentes componentes curriculares no exercício da docência.

Não se trata de inverter a lógica curricular vigente nos cursos de formação, fazendo com que a prática se torne mais importante que a teoria, muito pelo contrário, trata-se de conceber o currículo como expressão de uma unidade integrada que se materializa a partir de uma estreita união entre a instituição formadora e o espaço da atividade profissional. Ou ainda, é primordial 
promover a conexão da formação aos contextos de trabalho, por intermédio de "[...] parcerias inter-institucionais, nomeadamente com as escolas cooperantes na prática pedagógica, compartilhando os mesmos critérios, numa procura de coerência das intervenções nos processos de formação/socialização dos futuros professores" (ALONSO; SILVA, 2005, p. 55).

4. A última implicação diz respeito à compreensão do currículo de formação enquanto um projeto educativo. Tal compreensão nos ajuda, por um lado, conceber este currículo como processo articulado que supere a fragmentação e hierarquização do conhecimento, muitas vezes organizado em disciplinas que expressam muito mais a especialidade de um determinado profissional formador, do que a contribuição deste conhecimento no conjunto deste processo formativo.

Por outro lado, requer uma gestão flexível e compartilhada deste currículo, com o intuito de superar a prevalência do individualismo no exercício da docência, imprimindo o caráter participativo e colaborativo dos professores, enquanto sujeitos que, no coletivo, partilham as decisões curriculares, em diferentes contextos, em uma relação de interdependência e de negociação.

A aprendizagem e a vivência do coletivo, de forma intencional, torna-se imprescindivel no processo de formação inicial de professores, sobretudo, porque é neste exercício de troca entre os formandos que se inscreve a possibilidade da construção do conhecimento profissional pautado na valorização de práticas de cooperação e o "[...] fomento de experiências promotoras do desenvolvimento de uma consciência participativa" (FLORES, 2000, p. 157).

Deste modo, queremos, por fim, evidenciar que, se pretendemos processos escolarizantes integrados nos anos iniciais do Ensino Fundamental, há de se considerar, também, a integração curricular como perspectiva imprescindível no processo de formação inicial de professores, reafirmando, com Alonso e Silva (2005), que este modelo possibilita uma progressiva e consistente integração significativa de saberes, procedimentos e atitudes, dotando os formandos de competências que orientem a prática profissional num sentido de inovação e mudança das práticas educativas. 


\section{Referências}

ALONSO, Luísa. A abordagem de projecto curricular integrado como uma proposta de inovação das práticas na escola básica. Braga: Universidade do Minho/Instituto de Estudos da Criança. 2001 (Texto policopiado).

Para uma teoria compreensiva sobre integração curricular: o contributo do Projeto PROCUR. Investigação e Práticas, Porto, n. 5, p. 62-88, dez. 2002.

A construção de um paradigma curricular integrador. Braga: Universidade do Minho. 2004. Disponivel em: http://hdl.handle.net/1822/19232. Acesso em: 8 out. 2013.

Competências essenciais no currículo: que práticas nas escolas? In: CACHAPUZ, António; CHAVES, Idália Sá; PAIXÃO, Fátima (Org.). Saberes básicos de todos os cidadãos no século XXI. Lisboa: Conselho Nacional de Educação, Estudos e relatórios, 2004a.

Perfil profissional e projecto de formação. In: LOPES, Amélia (Org.). De uma escola a outra: temas para pensar a formação inicial de professores. Porto: Afrontamento, 2007.

SILVA, Carlos. Questões críticas acerca da construção de um currículo formativo integrado. In: ALONSO, Luísa; ROLDÃO, Maria do Céu. Ser professor do $1^{\circ}$ ciclo: construindo a profissão. Coimbra: Almedina, 2005.

(coord.); SOUSA, Francisco; GONÇALVES, Lucília Leite; MEDEIROS, Conceição; CARVALHINHO, Cristina. Referencial curricular para a educação básica na região autônoma dos Açores. Angra do Heroísmo: Secretaria Regional da Educação e Formação, 201 1. Disponível em: http://www.edu.azores.gov.pt/projectos/currregionaledubasica/ Paginas/referencialCREB.aspx. Acesso em: 9 out. 2013.

SOUSA, Francisco. Integração e relevância curricular. In: SOUSA, Francisco; ALONSO, Luísa; ROLDÃO, Maria do Céu. Investigação para um currículo relevante. Braga: Almedina/Centro de Investigação em Estudos da Criança, 2013.

BEANE, James. Integração curricular: a concepção do núcleo da educação democrática. Tradução Aurora Narciso. Lisboa: Didáctica Editora, 2002.

BRASIL. Constituição da República Federativa do Brasil (5 de outubro de 1988). Disponível em: http://www. planalto.gov.br/ccivil_03/constituicao/constituicao.htm. Acesso em: 10 out. 2013. 
Lei $\mathbf{n}^{\circ}$ 9.394, de 20 de dezembro de 1996. Dispõe sobre a Lei de Diretrizes e Bases da Educação Nacional. Disponível em: http://wwww.planalto.gov.br/ccivil_03/leis/ 19394.htm. Acesso em: 10 out. 2013.

Parecer $n^{\circ}$ 5, de 13 de dezembro de 2005. Dispõe sobre as Diretrizes Curriculares Nacionais para o Curso de Pedagogia. Disponível em: portal.mec.gov.br/cne/arquivos/ pdf/pcp05_05.pdf. Acesso em: 10 out. 2013.

Resolução $\mathbf{n}^{\circ}$ 7, de 18 de dezembro de 2010. Fixa as Diretrizes Curriculares Nacionais para o Ensino Fundamental de 9 (nove) anos. Disponível em: http:/ / www.seduc. ro.gov.br/portal/legislacao/RESCNE007_2010.pdf. Acesso em: 10 out. 2013.

CYRINO, Marina; SOUZA NETO, Samuel de. O estágio curricular supervisionado na experiência brasileira e internacional. Revista Educação em Questão, Natal, v. 48, n. 34, p. 86-1 15, jan./abr. 2014.

ESCUDERO, Juan Manuel. Las comunidades de aprendizaje y la reconstrucción organizativa y pedagógica de los centros escolares: una visión panorámica. In: SEMINÁRIO AS COMUNIDADES DE APRENDIZAGEM E A INOVAÇÃO EDUCATIVA, 2; 2010, Braga. Anais... Braga: Instituto de Educação/Universidade do Minho, 2010 (texto policopiado).

FEĹ́CIO, Helena Maria dos Santos. Análise curricular da escola de tempo integral na perspectiva da educação integral. Revista e Curriculum, São Paulo, v. 8, n. 1, p. 1-18. Abril de 2012.

FLORES, Maria Assunção. Currículo, formação e desenvolvimento profissional. In: PACHECO, José Augusto. Políticas de integração curricular. Porto: Porto Editora, 2000.

FULLAN, Michael; HARGREAVES, Andy. Por que vale a pena lutar? $\bigcirc$ trabalho de equipa na escola. Tradução Jorge Ávila de Lima Porto: Porło Editora, 2001.

GATTI, Bernadete Angelina. Formação de professores no Brasil: características e problemas. Educação \& Sociedade, Campinas, v. 31 , n. 1 13, p. 1355-1379, out / dez, 2010.

Políticas docentes no Brasil: um estado da arte. Brasília: UNESCO, 2011.

GIROUX, Henry. Os professores como intelectuais. Tradução Daniel Bueno. Porto Alegre: Artmed, 1997.

HARGREAVES, Andy. Os professores em tempos de mudança. $\bigcirc$ trabalho e a cultura dos professores na idade pós-moderna. Tradução Jorge Ávila de Lima. Lisboa: McGraw-Hill, 1998. 
A integração curricular no ensino fundamental e suas implicações para o currículo de formação de professores

LAVILLE, Christian; DIONNE, Jean. A construção do saber: manual de metodologia da pesquisa em ciências humanas. Tradução Heloísa Monteiro e Francisco Settineri. Porto Alegre: Artmed, 1999.

MOREIRA, Antonio Flavio Barbosa. Propostas curriculares alternativas: limites e avanços. Educação \& Sociedade, Campinas, v. 21 , n. 73, dez. 2000.

NÓVOA, Antonio. Devolver a formação dos professores aos professores. Cadernos de Pesquisa em Educação, Vitória, ano 9, v. 18, n. 35, p. 11-22, jan./jun. 2012.

PARO, Vitor Henrique. O currículo do ensino fundamental como tema de política pública: a cultura como conteúdo central. Ensaio: avaliação e políticas educacionais, Rio de Janeiro, v. 19, n. 72, jul./set. 2011.

PORTUGAL, Gabriela. Desenvolvimento e aprendizagem na Infância. In: ALARCÃO, Isabel; MIGUENS, Manuel (Org.). A educação das crianças dos 0 aos 12 Anos. Lisboa: Conselho Nacional de Educação, Estudos e Relatórios, 2009.

ROEGIERS, Xavier. Aprendizagem integrada. Situações do quotidiano escolar. Tradução Jeni Wolff. Porto Alegre: Artmed, 2006.

ROLDÃO, Maria do Céu. (2009). Que educação queremos para a infância? In: ALARCÃO, Isabel; MIGUENS, Manuel (Org.). A educação das crianças dos 0 aos 12 Anos. Lisboa: Conselho Nacional de Educação, Estudos e Relatórios, 2009.

$\bigcirc$ que é um currículo relevante? In: SOUSA, Francisco; ALONSO, Luísa; ROLDÃO, Maria do Céu (Org.). Investigação para um currículo relevante. Coimbra: Almedina, 2013.

SACRISTÁN, José Gimeno. A educação obrigatória: o seu sentido educativo e social. Tradução Jussara Rodrigues. Porto Alegre: Artmed, 2001.

SACRISTÁN, José Gimeno. A educação que ainda é possível: ensaios sobre a cultura para a educação. Tradução Valério Campos. Porto: Porto Editora, 2008.

ZEICHNER, Ken. Repensando as conexões entre a formação na universidade e as experiências de campo na formação de professores em faculdades e universidades. Educação, Santa Maria, v. 35, n. 3, p. 479-504, set./dez. 2010. 
Profa. Dra. Helena Maria dos Santos Felício Universidade Federal de Alfenas | Minas Gerais Instituto de Ciências Humanas e Letras Grupo de Pesquisa "Contextos Educacionais e Produção do Conhecimento" | Universidade Federal de Alfenas | Minas Gerais Grupo de Pesquisa "Currículo: Questões Atuais" | Pontifícia Universidade Católica | São Paulo Grupo de Pesquisa "Centro de Investigação em Estudos da Criança" | Universidade do Minho E-mail | helena.felicio@unifal-mg.edu.br; hsfelicio@gmail.com

Profa. Dra. Luísa Alonso Universidade do Minho | Portugal Instituto de Educação Grupo de Pesquisa "Centro de Investigação em Estudos da Criança" | Universidade do Minho E-mail | alonso@ie.uminho.pt

Recebido 30 mar. 2016 Aceito 6 jun. 2016 